Wilfrid Laurier University

Scholars Commons @ Laurier

Psychology Faculty Publications

Psychology

Spring 2007

\title{
Strengthening Ontario's System of Housing for People with Serious Mental IIIness
}

\author{
John Sylvestre \\ University of Ottawa \\ Lindsey George \\ McMaster University \\ Tim Aubry \\ University of Ottawa \\ Janet Durbin \\ Centre for Addiction and Mental Health \\ Geoffrey Nelson \\ Wilfrid Laurier University, gnelson@wlu.ca
}

See next page for additional authors

Follow this and additional works at: https://scholars.wlu.ca/psyc_faculty

Part of the Psychiatry and Psychology Commons

\section{Recommended Citation}

Sylvestre, John; George, Lindsey; Aubry, Tim; Durbin, Janet; Nelson, Geoffrey; and Trainor, John, "Strengthening Ontario's System of Housing for People with Serious Mental Illness" (2007). Psychology Faculty Publications. 16.

https://scholars.wlu.ca/psyc_faculty/16

This Article is brought to you for free and open access by the Psychology at Scholars Commons @ Laurier. It has been accepted for inclusion in Psychology Faculty Publications by an authorized administrator of Scholars Commons@ Laurier. For more information, please contact scholarscommons@wlu.ca. 


\section{Authors}

John Sylvestre, Lindsey George, Tim Aubry, Janet Durbin, Geoffrey Nelson, and John Trainor 


\title{
STRENGTHENING ONTARIO'S SYSTEM OF HOUSING FOR PEOPLE WITH SERIOUS MENTAL ILLNESS
}

\author{
JOHN SYLVESTRE \\ School of Psychology, and Centre for Research on Educational and Community Services \\ University of Ottawa \\ LINDSEY GEORGE \\ St. Joseph's Healthcare, and McMaster University \\ Hamilton, Ontario \\ TIM AUBRY \\ School of Psychology, and Centre for Research on Educational and Community Services \\ University of Ottawa \\ JANET DURBIN \\ Health Systems Research and Consulting Unit, Centre for Addiction and Mental Health \\ Toronto \\ GEOFFREY NELSON \\ Department of Psychology, Wilfrid Laurier University \\ Waterloo, Ontario \\ JOHN TRAINOR \\ Community Support and Research Unit, Centre for Addiction and Mental Health
}

Toronto

\begin{abstract}
This article describes recent work to support recommendations for improving Ontario's system of housing for people with serious mental illness. This multifaceted project engaged stakeholders in discussions concerning strategies for improving the system based on (a) values that underlie housing programs, (b) evidence of effective housing practices, (c) the current status of the system, and (d) international practices for monitoring community mental health systems. Stakeholders reviewed summaries of the work and discussed implications for improving the provincial system of housing and supports. Recommendations are made for improving the system, focusing on both regional and provincial level actions.
\end{abstract}

This work was funded by a grant from the Ontario Ministry of Health and Long-Term Care and the Ontario Mental Health Foundation. We acknowledge the contributions of Annabelle Sabloff who acted as research coordinator on this project. 
Housing is an essential component of an effective community mental health system for people with serious mental illness. Without accessible, good quality housing and support, successful community living and recovery are not possible. Ontario has provided housing dedicated to people with serious mental illness since the onset of deinstitutionalization. Since the 1960s, the system has grown substantially to encompass a variety of forms of housing and to become a cornerstone of the community mental health system. Despite its growth and importance, this housing system faces a number of significant challenges. It remains inadequate for meeting consumer demand, with very long waiting lists reported by most programs in the province. There is a lack of good data on the system, documenting who is being served and how they are being served, as well as on the needs of those who cannot access the system. This lack of information makes it difficult to effectively manage the system and to plan for its future.

In 2003, the Ontario Ministry of Health and Long-Term Care funded a research project to examine the province's dedicated housing system and to make recommendations for improving it. This paper describes the multifaceted project that was conducted to develop a foundation for planning system improvements. The project developed three foundations for system planning: (a) a vision for the system by identifying values that should guide the delivery of services, (b) research evidence about the status of the system and effective practices, and (c) consultations with stakeholders from across the province about directions for system improvement.

\section{THE ONTARIO HOUSING POLICY AND SYSTEM CONTEXT}

\section{The Policy Context}

Ontario has no policy specifically covering its housing system dedicated to people with serious mental illness. The most recent policy document, Making It Happen (Ontario Ministry of Health, 1999), broadly covered the mental health system. The document was seen as an extension of previous policy statements such as Putting People First (Ontario Ministry of Health, 1993) that set out a 10year strategy for reforming the mental health system including moving resources from institutions to the community. Making It Happen was intended to describe "how we can make sure that the mental health system works for people, with services that are effectively integrated and coordinated, and based on best practices" (p. 3). At the time the document was issued, the Ministry of Health (now the Ministry of Health and Long-Term Care) acquired all dedicated non-profit housing services for people with psychiatric disabilities from the Ministry of Municipal Affairs and Housing. The policy committed the Ministry of Health to establish a Mental Health Housing Steering Committee to oversee housing policy development and implementation $(1999$, p. 30). It is unclear whether the committee was ever created, but it is apparent that the promised comprehensive housing framework has not appeared.

Nonetheless, Making It Happen did provide principles for mental health system reform that can be applied to the mental health housing system. The seven principles included (a) placing the consumer at the centre of the mental health system, (b) developing services tailored to consumer needs with a view to improving quality of life, (c) improving choice and access, (d) linking and coordinating services to improve consumer movement within the system, (e) basing services on best practices, 
(f) protecting current funding, and (g) continuing investments and reinvestments in support of mental health reform and increasing the overall system capacity (Ontario Ministry of Health, 1999, p. 3). Making It Happen also described six characteristics of a reformed mental health system: (a) a comprehensive continuum of services to improve choice, (b) streamlined access through fewer entry points, (c) shared service models for consumers with multiple service needs, (d) reinvestments based on best practices and system needs, (e) clear system and service responsibility and accountability, and (f) decentralized regional structures that are responsive to regional needs (p. 7).

These principles and characteristics have been echoed in more recent national and provincial recommendations for improving mental health systems. Nationally, attention has been cast on the mental health system by the Standing Senate Committee on Social Affairs, Science and Technology, chaired by Senator Michael Kirby (Kirby, 2005; Shortt \& Sweetman, 2005). The committee based its thinking concerning the reform of the mental heath system on "the idea of a consumer-centred system with a focus on recovery and access to personalized care" (Kirby, 2005, p. S9). It identified a better integrated mental health system and maximal participation of consumers in all aspects of the planning and delivery of care as keys to achieving a more effective consumer-centred system (Kirby, 2005).

Hartford, Schrecker, Wiktorowicz, Hoch, and Sharp (2003) have noted that calls for improvements to the community-based support of people with serious mental illness have been recurrent in Ontario since the 1960s, but rarely met with a substantive policy response. Most recently, in 2000 and 2001 the Government of Ontario established nine regional Mental Health Implementation Task Forces and one provincial-level forum to develop recommendations for improvements to mental health services. The task forces' membership included service providers, consumers of services and their advocates, family members, and interested citizens. The reports consisted of comprehensive reviews of regional mental health systems and extensive recommendations for improvements. The reports were consistent in their call for consumer-centred mental health systems focused on promoting recovery (Wilson, 2005). Common recommendations included a greater integration of service providers, streamlined access to services, better accountability and system management, and addressing mental health issues in the workplace (Wilson, 2005).

The work of the Kirby committee and the Ontario Mental Health Implementation Task Forces strongly supported the principles outlined in Making It Happen, and also provided specific recommendations for actions. The focus of these documents, however, was on mental health systems as a whole, and there remains the need for work that focuses on developing a vision and recommendations for strengthening specific subsystems such as housing.

\section{The Ontario Housing System Context}

Although some consumers of mental health services in Ontario live in private homes or apartments that they own, rent, or share with family or friends, many are unable to gain access to private market homes because of their limited incomes and social networks. Many consumers seek access to Ontario's dedicated housing system for people with serious mental illness. A variety of housing types have emerged over the past 40 years, each reflecting different beliefs about the needs of consumers 
living in the community. These approaches include custodial, supportive, and supported housing. Custodial housing is offered in for-profit board-and-care settings with little or no rehabilitation support. The custodial housing system is administered separately from other forms of non-profit housing and has been resistant to reform (Sylvestre et al., 2001), despite the fact that it does not reflect any best practices evidence (Nelson \& Smith Fowler, 1987; Parkinson, Nelson, \& Horgan, 1999). Supportive housing is typically available in the form of congregate settings (converted houses, clustered apartments), and offers rehabilitation-oriented support aimed at enabling consumers to improve their community living skills. Supported housing, a strengths-based approach to housing, focuses on ensuring that consumers can get and keep normal housing in the community such as apartments (Carling, 1995). In this approach, consumers have access to individualized and flexible professional support that they choose and control.

Responsibility for the provision of housing for people with mental illness has shifted between different ministries and levels of government over the years. The housing portfolio currently resides with the Ministry of Health and Long-Term Care. The Ministry's central Supportive Housing Unit provides housing agencies with operating and rent subsidies to cover "bricks and mortar" costs, while Ministry Regional Offices provide agencies with funding to deliver supports to consumers both onand off-site. The system includes about 6,300 units that are managed by 74 community organizations, including 3,600 new units that were developed through two phases of the Mental Health Homelessness Initiative. About $43 \%$ of the available housing is custodial housing. The current provincial allocation is approximately $\$ 30$ million for housing and \$100 million for support.

\section{THE CURRENT STUDY}

This study was conducted with funding provided by the Ministry of Health and Long-Term Care with the goal of developing a foundation for system planning and making recommendations for improvements. The research team identified three foundations for this work. The first foundation is values. The study team assumed that values must be at the basis of decisions concerning the delivery of housing and community-based support services. Values-based approaches are increasingly being promoted for use in planning change in mental health services and organizations. These approaches aim to ensure that action is strongly connected to a values base (Nelson, Lord, \& Ochocka, 2001; Peirson, Prilleltensky, Nelson, \& Gould, 1997; Prilleltensky, Peirson, Gould, \& Nelson, 1997). The underlying belief is that housing is a fundamental right, is necessary for successful community integration, and that housing and support services must serve the interests of consumers.

The second foundation is evidence. Based on the directions provided by values, two types of evidence were sought. The first type was evidence of effective practices. The team conducted reviews to identify the qualities of effective housing and support services, and effective practices for monitoring the delivery of these services at a system level. The second type of evidence concerned gaps in the current system, including evidence of unmet and inadequately met needs as well as evidence of challenges facing the system. 
The third foundation is consultation. Planning requires a consideration and a synthesis of the views of the various stakeholders in the system and a balancing of the inevitable disagreements among them.

Work was divided into five components: (a) a review of housing values and standards, (b) a review of research evidence, (c) a snapshot of the current housing system, (d) a review of effective practices in monitoring mental health systems, and (e) consultations with provincial and regional level stakeholders. Each of these components produced a technical report that is available online at the Centre for Research on Educational and Community Services website (University of Ottawa, 2007). The technical reports contain descriptions of the methodologies employed in each project component.

\section{OVERVIEW OF THE RESEARCH}

\section{Housing Values Review}

An objective of this work was to identify values that can provide the Ministry of Health and LongTerm Care with a foundation for strengthening the housing system for persons with serious mental illness. The research team examined indexed peer-reviewed literature, as well as "grey literature" consisting of reports, websites, policy documents, and position papers. The review also included Mental Health Implementation Task Forces' reports commissioned by the Ministry. There were three steps in the literature review: (a) searching for documents, (b) selecting documents for review, and (c) performing a content analysis on the collected documents. Forty documents were identified through this search, and the resulting analysis identified eight housing values that were subsequently further reduced to six and grouped into two broad categories: therapeutic and citizenship housing values (Sylvestre, Nelson, Sabloff, \& Peddle, in press).

\section{Research Evidence Review}

This examination of past and current trends in housing and support for people with serious mental illness aimed to update previous literature reviews by Nelson and Smith Fowler (1987) and Parkinson et al. (1999), and focused primarily on studies published since 1998. To identify primary studies, the search drew on several literature reviews published within the last 5 years (Chilvers, MacDonald, \& Hayes, 2003; Fakhoury, Murray, \& Shepherd, 2002; Nelson, LaFrance, \& Aubry, in press; Newman, 2001; Rog, 2004; Rosenheck, 2000). Researchers also conducted a manual search of several journals that publish research on housing and mental health, and a computer search using several engines.

\section{Provincial Snapshot}

The purpose of this work was to provide a snapshot of the current status of the housing system in Ontario. The research team relied on three sources of information.

Comprehensive Assessment Project (CAP) studies. CAP studies were undertaken across Ontario to inform the process of mental health system change (Koegl, Durbin, \& Goering, 2004). Hospital 
CAPs were completed for clients of provincial psychiatric hospitals to more clearly identify how their needs could be served through community-based programs. Community CAPs were undertaken to assess whether current community mental health services were adequately meeting the needs of their clients. Data from these projects informed the work of the Mental Health Implementation Task Forces across the province (eight out of nine participated).

Mental Health Implementation Task Force reports. These reports were reviewed to identify regional data on the housing and support system in Ontario, as well as the challenges and recommendations described by the Task Forces.

Consultations with the Ministry of Health and Long-Term Care. Study team members consulted with Ministry staff to learn more about the housing and support system in the province as well as government practices, capacities, and plans for monitoring the system.

\section{Mental Health System Monitoring}

The objective of this work was to identify and review successful community mental health datacollection systems in industrialized countries that could provide lessons applicable to Ontario. A review of the published peer-reviewed and grey literature (technical reports, web-based information) on current community mental health data-collection systems was undertaken. From this review, the team identified three examples of best practices in data collection. Interviews with key informants involved with data collection systems were then conducted, including researchers, government officials, and caseworkers.

\section{Consultations with Provincial Reference Group and Regional Round-Table Discussions}

These consultations had two components.

Provincial reference group. A provincial reference group was convened to inform and guide the work of the study team. It was composed of provincial- and regional-level system stakeholders, including consumer organizations, a family organization, Ministry representatives, and service provider organizations. The reference group met on three occasions between April and June 2004, and members also provided feedback on a draft final report.

Regional round-table discussions. Round-table discussions were held in four regions of the province: Ottawa, Toronto, Thunder Bay, and Hamilton/Niagara. Fifty-seven consumers, family members, policy-makers, and service providers participated. The discussions, which were based on the values and evidence reviews conducted for this project, focused on identifying major challenges confronting the local system of supportive housing and community-based supports and on making recommendations for improving the system.

\section{SUMMARY OF FINDINGS}

\section{A Values Foundation}

The research team identified six values that to a great extent reflect the principles and characteristics of a reformed mental health system as articulated in Making It Happen (Ministry of Health, 
1999). Three values were characterized as therapeutic, referring to the quality of the relationship between the person in the housing and the immediate housing and neighbourhood setting: (a) choice and control, (b) quality, and (c) community integration. Choice and control refer to the ability of individuals to choose and to have some control over the housing and supports they receive. Quality points to the importance of housing that is of good quality and well located, while community integration describes housing that is non-stigmatizing and that enables individuals to maintain or develop relationships (Sylvestre et al., in press).

A second set of three values was characterized as citizenship housing values, referring to consumers being able to take control of their lives by acting on their rights. Whereas the therapeutic values are associated with specific housing situations that affect the mental health of consumers, citizenship values reference consumers' participation in broader systems at the level of programs, agencies, mental health systems, and society more generally. The citizenship values of (a) access and affordability, (b) accountability, and (c) housing rights and legal security of tenure mean that consumers should have fair and equitable access to resources that are responsive to their needs, sufficient income to meet those needs, and that consumers should be informed and able to act on their rights in acquiring and maintaining housing (Sylvestre et al., in press).

\section{An Evidence Foundation}

Snapshot of the current housing system. Data on over 4,000 individuals in the province's dedicated housing system were available from the CAP studies. These data reveal how the current system falls well short of the identified values for housing, as well as the characteristics of a reformed mental health system described in Making It Happen (Ministry of Health, 1999). First, the data reveal a need for dedicated housing and support in the province that far exceeds the supply. Furthermore, about half of those who do gain access to the system are housed in supervised congregate settings, even though few of these individuals require this level of supervision. For example, of those currently in 24-hour high support settings, only $14 \%$ were identified as requiring that level of support, while the majority were identified as able to live independently in the community if they received daily (45\%) or weekly (26\%) support. This means that within the existing housing stock, there is an oversupply of supervised congregate housing and a relative paucity of independent housing such as apartments. At the same time, there is also a smaller number of consumers who either need higher support options or reside in settings where the support component is inadequate to meet their needs.

These findings suggest that there is a considerable mismatch in the housing system. This incongruity appears to be driven both by inadequate supply of some types of housing and by insufficient supports in others. Notably, the inadequacy of available supports prevents consumers from improving their living skills and gaining access to housing better suited to their needs. Custodial programs are typically unable to provide a high level of clinical or rehabilitative care, while many people in supportive housing could live in independent settings if they had access to more appropriate support.

Review of research evidence. The review of research evidence suggested that choice and control are essential elements of consumer recovery and empowerment (e.g., Srebnik, Livingston, Gordon, \& King, 1995). When consumers have choice and control over their housing, they are more likely to 
experience enhanced quality of life and improved community functioning (Nelson, Sylvestre, Aubry, George, \& Trainor, 2007; Srebnik et al., 1995). Choice and control should enable consumers to access the resources that they desire, a value expressed in the supported housing approach in which consumers have access to normal, independent housing (e.g., apartments) in the community with flexible and individualized supports. Consumer preference studies consistently show that most consumers want to live in their own apartments or houses (e.g., Tanzman, 1993). However, a study in London, Ontario, has shown that the majority of consumers surveyed do not live in the type of housing that they prefer (Nelson, Hall, \& Forchuk, 2003).

Other research evidence suggests that housing quality—physical characteristics, furniture, and privacy — has a strong relationship to the well-being of consumers (Parkinson et al., 1999). Additionally, Parkinson et al. reported that housing that is physically integrated into the community so that one cannot distinguish that mental health consumers live in the residence increases the likelihood of social integration, likely as a result of reduced stigma and isolation.

A number of controlled, longitudinal studies have been conducted that clearly demonstrate that housing subsidy programs are successful in enabling consumers to gain access to, and to maintain, stable housing (Dickey et al., 1996; Dickey, Latimer, Powers, Gonzalez, \& Goldfinger, 1997; Goldfinger et al., 1997; Goldfinger et al., 1999; Gulcur, Stefancic, Shinn, Tsemberis, \& Fischer, 2003; Hurlburt, Wood, \& Hough, 1996; Newman, Reschovsky, Kaneda, \& Hendrick, 1994; Rog \& Randolph, 2002; Rosenheck, Kasprow, Frisman, \& Liu-Mares, 2003; Shern et al., 1997; Tsemberis, 1999; Tsemberis \& Eisenberg, 2000; Tsemberis, Gulcur, \& Nakae, 2004; Tsemberis, Moran, Shinn, Asmussen, \& Shern, 2003). These programs include Section 8 certificates in the United States that enable people "to pay a fixed 30\% of their income for a private rental unit" (Hurlburt et al., 1996, p. 310). While concerns are sometimes raised that some consumers do not have the capacity to live independently in the community, the research cited above clearly indicates that this is not the case. The participants in these studies not only have serious mental illness, but also histories of homelessness, substance abuse, and a variety of other psychosocial and health problems. With individualized support, these individuals are able to live independently and to maintain their housing.

One study examined the costs of various housing models. In an experimental comparison of independent living (supported apartments) and group living, Dickey et al. (1997) found that the average housing costs were significantly lower for independent living $(\$ 13,042)$ than for group living $(\$ 42,829)$, while treatment and case management costs were not significantly different.

Review of mental health monitoring-system evidence. A primary finding from this review was that there were few jurisdictions, internationally, that had fully developed and implemented monitoring strategies for community mental health systems. The review identified three best examples of sufficiently implemented data-collection systems located in Australia, California, and Ohio. However, even in these jurisdictions the data collection systems were at a relatively early stage of development, and the collected data were not yet being fully used to improve mental health services.

A structured interview was conducted with two key informants from each of the three jurisdictions with program monitoring systems in place. From these interviews, eight factors were identified 
that facilitated the implementation of the monitoring systems: (a) the availability of online forms to facilitate both data entry and prompt data processing and analysis, (b) the training of program staff to ensure accurate and timely data collection, (c) the availability of prompt assistance to caseworkers from government personnel for questions or concerns, (d) the aggregation of data to prevent performance comparison between caseworkers, (e) the use of data collection tools to make demands on program staff manageable, (f) the integration of tools in the assessment process to help case-level service planning, (g) a commitment by program managers to ensure successful implementation, and (h) client information that is easily summarized and accessible to clinicians.

Several lessons emerged from key informant interviews that could be applied to assist Ontario in developing a data collection system: (a) the need for a centralized responsibility for data collection within the Ministry of Health and Long-Term Care, (b) the need for regular training at the right level (e.g., caseworkers or front-line staff who collect that data), (c) an investment of additional resources for data collection to prevent overtaxing program staff, and (d) the involvement of all levels of agency and government in the planning and implementation of the program monitoring system in order to ensure commitment to and maximal usefulness of the system monitoring program.

\section{A Foundation of Consultation}

As findings from this work emerged, they were shared with the project's provincial reference group. A summary of this work, with the exception of system monitoring findings, was also provided to participants in the regional round-table discussions. There was general agreement among stakeholders that both values and evidence should drive system development, and that housing should be recognized as a determinant of health and a basic human right. Issues in moving toward a values- and evidence-based approach included dealing with the lack of resources, addressing the paucity of research to guide evidence-based decision making, defining the ingredients of effective support, and developing reliable tools for assessing need and for service planning.

Identified system strengths were often unique to specific communities. Strengths included the range of providers, common values, collaboration, strategies to address diversity, innovative programs, service agreements between providers, partnerships with private landlords, and partnerships with hospitals. For example, one round table was held in a rural, northern community that has adopted a supported housing approach, helping individuals to live independently with the assistance of rent supplements and individualized support. Broader system-level strengths included the Ministry of Health and Long-Term Care's dedicated housing unit, the stability of Ministry housing stock, the Tenant Protection Act, and provincial and municipal government collaboration.

The barriers and challenges identified were wide ranging and reflected both systemic and local issues. These barriers included the gap between income supports and rents, lack of affordable housing, the inability of consumers to move to more independent housing because of limited choices, over supply of custodial models, uncertainty concerning the type and number of housing units (congregate and independent) that would match consumer demand, relationships with private landlords, access to mental health services, tensions between housing and mental health providers, community opposition 
and other housing development issues, hospital discharge planning, language that focuses on disability rather than recovery, and the challenge of meeting the unique needs of rural and small communities as well as diverse communities and specific populations.

\section{Comparison of Findings from Reviews of Values and Evidence, and Consultations}

There are notable discrepancies between findings from each of the components of this project. First, the values foundation is not reflected either in the current housing system or in the existing research evidence base. In terms of the current system, fundamental information is lacking concerning particular values such as housing quality, community integration, and housing rights. It is clear, however, that the system offers limited choice, control, and accountability. In terms of the research evidence, there is some evidence related to the therapeutic housing values of choice and control, quality, and community integration, but a paucity of research related to the citizenship values of access and affordability, housing rights and legal tenure, and accountability (Sylvestre et al., in press). Much of the prior research has been interested in identifying the effects of proximal housing environments on consumer well-being, rather than in identifying housing program and system processes and policies that may promote greater citizenship and enfranchisement.

Second, the review of system monitoring practices shows that the lack of monitoring of community mental health services in Ontario is consistent with most other jurisdictions. The review suggests a number of practical steps that can be undertaken to implement such a system to track consumer-level outcomes. The findings from stakeholder consultations, however, suggest that these systems should monitor how services are delivered in addition to housing outcomes. Among the concerns of stakeholders were issues related to assessing fit between individuals and available housing options, and maintaining relationships with landlords. Stakeholders were generally interested in practical strategies for improving the delivery of services. Notably, the available research evidence, with its focus on individual-level outcomes rather than program processes, was unable to speak to these concerns.

\section{SUMMARY OF RECOMMENDATIONS}

Based on this work, the research team made recommendations for strengthening the housing system. The recommendations are wide-ranging and include coordinated provincial- and regional-level action. Although ambitious, the recommendations reflect the current challenges faced by this critical system. Whereas there have been efforts in the province to increase the number of available housing units, there have been few efforts to strengthen the system as a system.

\section{Increase the Capacity of Supportive Housing and Community Support Systems}

Recognize housing as a basic human right fundamental to recovery. Everyone with a disability arising from mental illness should have access to good quality housing and support. The Ministry of Health and Long-Term Care should create a variety of new housing options across the province to

eliminate homelessness and to meet housing needs. Along with the increase in housing units, there 
must be an increase in the availability of support services and better coordination of these services with housing programs.

Strengthen existing services. Existing housing and support programs should be strengthened to meet the needs of consumers who are poorly served. This would involve increased financial support to maintain existing housing, as well as to provide training for housing and community support staff to work effectively with people with complex needs (e.g., concurrent disorders) and people from diverse ethno-cultural and linguistic backgrounds. Our best evidence suggests that there are two poorly met needs in the province. The most significant need is for more independent housing in the form of apartments. Addressing this need would free up space in higher support homes for those who would benefit more from them. There is also a significant need for higher support congregate housing for consumers with complex needs, long histories of institutionalization, and/or concurrent disorders.

Rationalize use of existing resources. Available data suggest that many consumers are in housing or receive support that is not appropriate for their needs, offering either too much or too little structure and support. The Ministry should ensure that agencies that receive enhanced funding to offer more support give first priority to consumers who require this level of structure and support.

\section{Develop Regionally Based Coordination and Planning}

Create regional housing and support teams. Regional housing and support teams would consist of peer workers and professionals working in partnership with consumer groups, service providers, and families. These teams would act as a clearinghouse for local housing information, as well as provide ongoing education to consumers about housing rights and how to keep their housing. The teams would support service providers by disseminating information about best practices, analyzing and disseminating findings from local system monitoring, and planning strategies to strengthen the delivery of local services.

Create regional coordinated access. Coordinated access would create a single point of access to the system. By adopting a single application form and process, consumers would have access to a complete inventory of housing and community support options from which they could choose. Coordinated access would also facilitate the creation of a database to aid in system monitoring by identifying how consumers are housed and by tracking those on waiting lists.

Provide comprehensive and collaborative planning for housing and community supports. Regional housing and support teams would provide planning in each region of the province to assist consumers in choosing the right housing and supports for them. Planning would be comprehensive, taking into account a variety of functional, psychological, and social factors. Optimal planning is also collaborative, involving the consumer at the centre supported by professionals, family, and friends.

\section{Support the Provision of High Quality Services}

Set provincial standards. The Ministry of Health and Long-Term Care should work with a variety of stakeholders to develop general standards for housing and support services. The Ministry should 
reform custodial housing so that it reflects all standards expected of supportive and supported housing including respect for the Tenant Protection Act, privacy, client control over living spaces, and access to active rehabilitation and community supports.

Develop collaborative approaches for the development of standards, continuous innovation, and program improvement. Housing providers in Ontario have identified challenges in learning about and translating best practices into practical service improvements. They have voiced an interest in learning from each other about strategies for improving their services. At the provincial level, a working group composed of Ministry representatives, provincial associations, consumer groups, and researchers should be convened. This group would work to establish a collaborative process for developing standards for supportive housing in the province. It would also establish a collaborative review process to assess whether providers are meeting these standards, and to support them to achieve them when they are not.

\section{Identify Priorities for System Monitoring}

Monitor service needs, service use, and consumer satisfaction. The Ministry should pursue strategies for gathering consumer-level data including information on who becomes housed, how they are housed, how long they stay housed, their use of other services, their participation in education or work, and their income. The Ministry should also monitor on a regular basis levels of consumer satisfaction with the services they receive, including their suggestions for improving these services.

Monitor programs and the system, and fund strategic program evaluation. System monitoring should occur at two levels. A regional program review process should monitor how housing and community support programs are delivered in each region and the extent to which these programs are meeting provincial standards. At the provincial level, aggregate data should be collected to monitor how programs are being delivered in the province. In addition, the Ministry should contract with researchers to evaluate promising pilot innovations and new systematic and programmatic initiatives that, once shown to be effective, could be diffused.

\section{Ensure Affordability}

Provide housing subsidies and help consumers to escape poverty. The Ministry of Health and Long-Term Care should aggressively pursue strategies to ensure that consumers have access to housing subsidies of a sufficient amount to gain access to good quality, independent housing in their communities. The Ministry should work with other ministries to ensure that the Ontario Disability Support Program offers consumers sufficient income to escape poverty. Wilton (2004) has reported that social assistance benefits in Ontario declined by 13\% from 1994 to 2001, a decline that resulted from changes in government policy. The personal needs allowance of $\$ 112$ per month that mental health consumers receive has not been raised since 1992. In a qualitative study of mental health consumers residing in custodial housing in Hamilton, Ontario, Wilton documented the deleterious effects of poverty on consumers' quality of life and community integration. A threshold that should be targeted is ensuring that 
STRENGTHENING ONTARIO'S SYSTEM OF HOUSING

consumers spend less than $30 \%$ of their income on housing. In addition, local housing and support planning should address issues of food security and help consumers to meet their daily living expenses.

\section{Provide System Leadership}

Strengthen provincial leadership. Along with the proposed increased regional role, there is a need for centralized provincial leadership. The existing Supportive Housing Unit should be strengthened so that it can play a more effective management and planning role in the housing system. This would involve (a) developing and supporting working groups to establish system-monitoring priorities and strategies, standards, and means of promoting good practices in housing and support in the province; (b) collecting, analyzing, and interpreting provincial and regional data; and (c) actively managing the housing portfolio, coordinating better with the community support portfolio, and system development planning.

\section{DISCUSSION}

Adequate housing is internationally recognized as a fundamental right (United Nations HABITAT, 2003) and Canada has long been a signatory to international agreements that all citizens should have access to adequate housing (Porter, 2004). In Ontario, the location of a dedicated housing portfolio within the health ministry reflects an additional recognition that housing is an essential component of the community mental health system and a necessary health service for people who by virtue of a psychiatric disability cannot access or retain housing in the regular housing market. Ontarians expect their publicly funded health care system to provide them with the highest quality of care and easy access to the best resources. They are understandably concerned and frustrated when shortages, underfunding, or poor planning lead to increased waiting times and poor services that threaten their health. Ontarians with serious mental illness are justified in expecting that the health care system should provide them with the best quality of services - services that are essential for their well-being. Unfortunately, we seem to routinely accept that the community mental health system in general, and the dedicated system of housing in particular, will be inadequate.

It is certain that questions of the affordability of an enhanced, dedicated mental health housing system will be raised when available funds for health care appear to be stretched so thin. Unfortunately, a complete picture of costs associated with these housing services is not available. Studies of supported housing approaches have produced contradictory findings of cost benefits, although they have found clear evidence of improved housing outcomes (Gulcur et al., 2003; Rosenheck, 2000; Rosenheck et al., 2003). As previously noted, Dickey et al. (1997) found that supportive housing (group living) is more expensive than supported housing (independent living), suggesting that if there were a shift from custodial or group living to supported housing, costs could be reduced and potentially more consumers could be better served. Supported housing options also have the benefit of relatively low start-up costs because there are no costs associated with locating, financing, and renovating existing properties or building new ones. Irrespective of the housing approach, community housing is significantly cheaper and more humane than hospitalization or other forms of institutionalization. 
Housing is a relatively unique aspect of the health care system in that it significantly touches domains that are associated with privacy, emotional attachment, and personal control. Housing that feels like home is not run by institutional rules or treatment regimens; good quality housing is secure and empowering. Given the evidence linking the detrimental effects on health from living in poorer housing that offers less choice and control, there are no compelling reasons, economic or otherwise, to justify not further investing in and strengthening this system according to the values advanced here.

Notwithstanding these arguments, it is unrealistic to expect any time soon a wholesale revamping of the system, and a more pragmatic approach requires the identification of particular recommendations that could proceed more expeditiously. As a first step, we recommend strengthening the system through investments that will support the housing community in identifying, implementing, and monitoring good practice in the province. Ontario has a deep pool of experience in this sector that could be better tapped so that service providers, consumers, and their advocates can learn from one another about effective ways of organizing and delivering these services. Second, we recommend creating more supported housing in the form of independent apartments. The use of additional housing subsidies or head-lease arrangements requires fewer up-front costs than supportive housing (e.g., the acquisition and renovation of new properties), and is a flexible option in that this funding could be used to acquire housing in locations where consumers prefer to live (including smaller towns in more rural regions). The creation of new supported housing would also potentially free up supportive housing spaces.

Our recommendations fit well with recent developments in the province. The Ontario government has created Local Health Integration Networks (LHINs) in 14 regions of the province that will be charged with managing health care services, including community mental health services. Greater regional-based planning is expected to lead to more effective integration and deployment of resources according to local needs, including the needs of rural communities. Our regional-level recommendations would help the LHINs to better integrate and coordinate housing and support services, particularly through the creation of regional housing and support teams, while our provincial-level recommendations address standards and system monitoring. The devolution of powers to the LHINs, however, makes these recommendations more difficult to implement as there are now 14 regional bodies rather than one provincial-level decision-making body that must be persuaded to act.

The interest of the Ministry of Health and Long-Term Care in commissioning this work provides an exciting opportunity to further develop a system of housing and supports that are grounded in provincial policy and implemented within local communities. This work suggests that there is readiness for change that is consistent with consumer preference and a recovery vision, and signals a shift toward integrating both values and evidence in shaping system development.

\section{RÉSUMÉ}

Dans cet article, nous présentons des travaux réalisés récemment et sur lesquels s'appuient des recommandations qui permettraient d'améliorer le système ontarien d'aide au logement pour les personnes vivant avec de sérieux problèmes de santé mentale. Ce projet à multiples facettes a rassemblé divers intervenants, qui ont discuté de stratégies à mettre en œuvre pour améliorer le système, et ce, à 


\section{STRENGTHENING ONTARIO’S SYSTEM OF HOUSING}

partir de 4 éléments: (a) les valeurs qui sous-tendent les programmes de logement; (b) des données qui montrent l'efficacité de certaines pratiques en matière de logement; (c) l'état actuel du système; et (d) des pratiques de surveillance de l'application de systèmes de santé mentale communautaire au niveau international. Les participants ont examiné des résumés des travaux, et ont discuté de leurs implications sur l'amélioration du système ontarien de soutien au logement. L'article présente ensuite des recommandations qui permettraient d'améliorer ce système, grâce à des mesures prises à la fois aux niveaux régionaux et provincial.

\section{REFERENCES}

Carling, P.J. (1995). Return to community: Building support systems for people with psychiatric disabilities. New York: Guilford Press.

Chilvers, R., MacDonald, G.M., Hayes, A.A. (2003). Supported housing for people with severe mental disorders (Cochrane Review). In The Cochrane Library, Issue 1. Oxford: Update Software.

Dickey, B., Gonzalez, O., Latimer, E., Powers, K., Schutt, R., \& Goldfinger, S. (1996). Use of mental health services by formerly homeless adults residing in group and independent housing. Psychiatric Services, 47 , $152-158$.

Dickey B., Latimer, E., Powers, K., Gonzalez, O., \& Goldfinger, S. (1997). Housing costs for adults who are mentally ill and formerly homeless. Journal of Mental Health Administration, 24, 291-305.

Fakhoury, W.K.H., Murray, A., \& Shepherd, G. (2002). Research in supported housing. Social Psychiatry and Psychiatric Epidemiology, 37, 301-315.

Goldfinger, S.M., Schutt, R.K., Tolomiczenko, G.S., Seidman, L., Penk, W.E., Turner, W., \& Caplan, B. (1999). Housing placement and subsequent days homeless among formerly homeless adults with mental illness. Psychiatric Services, 50, 674-679.

Goldfinger, S.M., Schutt, R.K., Tolomiczenko, G.S., Turner, W.M., Ware, N., Penk, W.E., Ableman, M.S., Avruskin, T.L., Breslau, J., Caplan, B., Dickey, B., Gonzalez, O., Good, B., Hellman, S., Lee, S., O’Bryan, M., \& Seidman, L. (1997). Housing persons who are homeless and mentally ill: Independent living or evolving consumer households? In W. Breaky \& J. Thompson (Eds.), Mentally ill and homeless: Special programs for special needs (pp. 29-49). Amsterdam, The Netherlands: Harwood Academic Publishers.

Gulcur, L., Stefancic, A., Shinn, M., Tsemberis, S., \& Fischer, S.N. (2003). Housing, hospitalization, and cost outcomes for homeless individuals with psychiatric disabilities participating in continuum of care and housing first programmes. Journal of Community and Applied Social Psychology, 13, 171-186.

Hartford, K., Schrecker, T., Wiktorowicz, M., Hoch, J.S., \& Sharp, C. (2003). Four decades of mental health policy in Ontario, Canada. Administration and Policy in Mental Health, 31, 65-73.

Hurlburt, M.S., Wood, P.A., \& Hough, R.L. (1996). Providing independent housing for the homeless mentally ill: A novel approach to evaluating long-term longitudinal housing patterns. Journal of Community Psychology, 24, 291-310.

Kirby, M. (2005). Mental health reform for Canada in the $21^{\text {st }}$ century: Getting there from here. Canadian Public Policy, 31(Suppl. 1), 5-12. Retrieved September 26, 2005, from http://economics.ca/cpp/en/specialissue/php

Koegl, C., Durbin, J., \& Goering, P. (2004). Mental health services in Ontario: How well is the province meeting the needs of persons with serious mental illness? Toronto: Centre for Addiction and Mental Health.

Nelson, G., Hall, G.B., \& Forchuk, C. (2003). Current and preferred housing of psychiatric consumer/survivors. Canadian Journal of Community Mental Health, 22(1), 5-19.

Nelson, G., Lafrance, A., \& Aubry, T. (in press). A review of the literature on the effectiveness of housing and support, assertive community treatment, and intensive case management for persons with mental illness who have been homeless. American Journal of Orthopsychiatry.

Nelson, G., Lord, J., Ochocka, J. (2001). Shifting the paradigm in community mental health: Towards empowerment and community. Toronto: University of Toronto Press.

Nelson, G., \& Smith Fowler, H. (1987). Housing for the chronically mentally disabled: Part II - Process and outcome. Canadian Journal of Community Mental Health, 6, 79-91. 
Nelson, G., Sylvestre, J., Aubry, T., George, L., \& Trainor, J. (2007). Housing choice and control, housing quality, and control over professional support as contributors to the subjective quality of life and adaptation to community living of people with severe mental illness. Administration and Policy in Mental Health and Mental Health Services Research, 34, 89-100.

Newman, S.J. (2001). Housing attributes and serious mental illness: Implications for research and practice. Psychiatric Services, 52, 1309-1317.

Newman, S.J., Reschovsky, J.D., Kaneda, K., \& Hendrick, A.M. (1994). The effects of independent living on persons with chronic mental illness: An assessment of the Section 8 Certificate Program. The Milbank Quarterly, 72, 171-198.

Ontario Ministry of Health. (1993). Putting people first: The reform of mental health services in Ontario. Toronto: Queen's Printer for Ontario.

Ontario Ministry of Health. (1999). Making it happen: Implementation plan for mental health reform. Toronto: Queen's Printer for Ontario.

Parkinson, S., Nelson, G., \& Horgan, S. (1999). From housing to homes: A review of the literature on housing approaches for psychiatric consumer/survivors. Canadian Journal of Community Mental Health, 18, 145-164.

Peirson, L., Prilleltensky, I., Nelson, G., \& Gould, J. (1997). Planning mental health services for children and youth: Part II - Findings of a value-based community consultation project. Evaluation and Program Planning, 20(2), 173-183.

Porter, B. (2004). The right to adequate housing in Canada. In J.D. Hulchanski \& M. Shapcott (Eds.), Finding room: Policy options for a Canadian rental housing strategy (pp. 69-79). Toronto: University of Toronto Press.

Prilleltensky, I., Peirson, L., Gould, J., \& Nelson, G. (1997). Planning mental health services for children and youth: Part I - A value-based approach. Evaluation and Program Planning, 20(2), 163-172.

Rog, D.J. (2004). The evidence on supported housing. Psychiatric Rehabilitation Journal, 27, 334-344.

Rog, D.J., \& Randolph, F.L. (2002). A multisite evaluation of supported housing: Lessons from cross-site collaboration. New Directions in Mental Health, 94, 61-72.

Rosenheck, R. (2000). Cost-effectiveness of services for mentally ill homeless people: The application of research to policy and practice. American Journal of Psychiatry, 157, 1563-1570.

Rosenheck, R., Kasprow, W., Frisman, L., \& Liu-Mares, W. (2003). Cost-effectiveness of supported housing for homeless persons with mental illness. Archives of General Psychiatry, 60, 940-951.

Shern, D.L., Felton, C.J., Hough, R.L., Lehman, A.F., Goldfinger, S., Valencia, E., Dennis, D., Straw, R., \& Wood, P.A. (1997). Housing outcomes for homeless adults with mental illness: Results from the secondround McKinney program. Psychiatric Services, 48, 239-241.

Shortt, S.E.D., \& Sweetman, A. (2005). Introduction: Mental health reform for the $21^{\text {st }}$ century. Canadian Public Policy, 31(Suppl. 1), 1-4. Retrieved September 26, 2005 from http://economics.ca/cpp/en/specialissue/php

Srebnik, D., Livingston, J., Gordon, L., \& King, D. (1995). Housing choice and community success for individuals with serious and persistent mental illness. Community Mental Health Journal, 31, 139-152.

Sylvestre, J., Nelson, G., Sabloff, A., \& Peddle, S. (in press). Housing for people with serious mental illness: A comparison of values and research. American Journal of Community Psychology.

Sylvestre, J., Trainor, J., Hopkins, M., Anucha, U., Ilves, P., \& Ramsundar, N. (2001). À propos de la stabilité du logement chez des personnes prises avec des troubles mentaux graves. Nouvelles Pratiques Sociales, 14(2), $59-74$.

Tanzman, B.H. (1993). Researching the preferences for housing and supports: An overview of consumer preference surveys. Hospital and Community Psychiatry, 44, 450-455.

Tsemberis, S. (1999). From streets to homes: An innovative approach to supported housing for homeless adults with psychiatric disabilities. Journal of Community Psychology, 27, 225-241.

Tsemberis, S., \& Eisenberg, R.F. (2000). Pathways to housing: Supported housing for street-dwelling homeless individuals with psychiatric disabilities. Psychiatric Services, 51, 487-493.

Tsemberis, S., Gulcur, L., \& Nakae, M. (2004). Housing first, consumer choice, and harm reduction for homeless individuals with a dual diagnosis. American Journal of Public Health, 94, 651-656. 
Tsemberis, S., Moran, L., Shinn, M., Asmussen, S.M., \& Shern, D.L. (2003). Consumer preference programs for individuals who are homeless and have psychiatric disabilities: A drop-in center and a supported housing program. American Journal of Community Psychology, 32, 305-317.

United Nations. HABITAT and Office of the High Commissioner for Human Rights. (2003). United Nations housing rights programme. Retrieved June 6, 2005, from http://www.unhabitat.org/programmes/ housingrights/

University of Ottawa. Centre for Research on Educational and Community Services. (2007). Retrieved May 8, 2007, from http://www.socialsciences.uottawa.ca/crcs/eng/publ.asp?type=mentalhealth

Wilson, M. (2005). Getting there from here: Next steps. Canadian Public Policy, 31(Suppl. 1), 69-74. Retrieved September 26, 2005, from http://economics.ca/cpp/en/specialissue/php

Wilton, R. (2004). Putting policy into practice? Poverty and people with serious mental illness. Social Science and Medicine, 58, 25-39. 